\title{
Who becomes a sperm donor: personality characteristics in a national sample of identifiable donors
}

\author{
Gunilla Sydsjö, C Lampic, S Brandstrom, J Gudmundsson, P-O Karlstrom, \\ N G Solensten, A Thurin-Kjellberg and A Skoog Svanberg
}

\section{Linköping University Post Print}

N.B.: When citing this work, cite the original article.

This is the authors' version of the following article:

Gunilla Sydsjö, C Lampic, S Brandstrom, J Gudmundsson, P-O Karlstrom, N G Solensten, A Thurin-Kjellberg and A Skoog Svanberg, Who becomes a sperm donor: personality characteristics in a national sample of identifiable donors, 2012, British Journal of Obstetrics and Gynecology, (119), 1, 33-39.

which has been published in final form at: http://dx.doi.org/10.1111/j.1471-0528.2011.03172.x

Copyright: Wiley-Blackwell

http://eu.wiley.com/WileyCDA/Brand/id-35.html

Postprint available at: Linköping University Electronic Press

http://urn.kb.se/resolve?urn=urn:nbn:se:liu:diva-74152 


\section{Who becomes a sperm donor - personality characteristics in a national sample of identifiable donors.}

Sydsjö Gunilla ${ }^{1}$, Lampic Claudia,${ }^{2}$ Brändström Sven ${ }^{3}$, Gudmundsson Johannes ${ }^{4}$, Karlström Per-Olof ${ }^{5}$, Solensten Nils Gunnar ${ }^{6}$, Thurin-Kjellberg Ann ${ }^{7}$, Skoog Svanberg Agneta ${ }^{4}$

1. Division of Obstetrics and Gynecology, Department of Clinical and Experimental Medicine, Faculty of Health Sciences, Linköping University, Department of Obstetrics and Gynecology in Linköping, County Council of Östergötland, Linköping, Sweden

2. Department of Neurobiology, Care sciences and Society, Karolinska Institute, Sweden

3. Inst for Neuroscience and Physiology, Psychiatry and Neurochemistry section,

Forensic Psychiatry, University of Gothenburg, Sweden

4. Dept. Of Women's and Children's Health, Uppsala University, Uppsala, Sweden

5. Clintec, Karolinska Institutet, Dept of clinical Science, Intervention and Technology

Div. of obstetrics/gynecology, Karolinska University Hospital, Sweden

6. IVF-kliniken Umeå in collaboration with Umeå University Hospital, Sweden

7. Inst of Clinical Sciences, Sahlgrenska Academy, Gothenburg, Sweden

Correspondence: Gunilla Sydsjö,

Division of Obstetrics and Gynecology, Department of Molecular and Clinical Medicine

Faculty of Health Sciences, Linköping University,

SE - 58185 Linköping, Sweden

Tel: +4613223167; fax: +4613148156

Email: Gunilla.Sydsjo@lio.se

Short running title: Sperm donors' personality characteristics 


\begin{abstract}
Objective: To study personality characteristics of identifiable sperm donors in a national sample in comparison with the same characteristics in a control group.

Design: Descriptive study.

Setting: All clinics ( $n=7)$ performing gamete donation in Sweden.

Subjects: All Swedish sperm donors recruited during 2005-2008. An age-matched group of Swedish men served as controls.

Method: Standardized questionnaires were used to measure personality

Main outcome measures: Demographics, Temperament and Character instrument (TCI).

Results: Mean age for the donors was $33.8 \pm 7.8$ years $(18-56$ years). About one third $(36.5 \%)$ of the donors had biological children of their own. With regard to personality, significant differences were present on Harm Avoidance with lower means for sperm donors $(\mathrm{p}=.002 ; 95 \% \mathrm{CI}:-3.74--0.85)$ and on Self Directedness and Cooperativeness with higher means for donors ( $\mathrm{p}=.002$; 95\%CI: $0.97-4.19, \mathrm{p}=.001 ; 95 \% \mathrm{CI}: 0.75-2.95)$, respectively) compared to controls. This indicates that the donors in general feel less worried and suffer less from uncertainty, shyness and fatigability than controls. They also perceive themselves as being autonomous with a capacity to take responsibility, to behave in a goal directed manner, to be resourceful and self-acceptant and to behave in a manner guided by meaningful values and goals. Furthermore, they describe themselves as being well integrated in humanity or society and having a good capacity for identification with and acceptance of other people.
\end{abstract}

Conclusion: The screening process at the clinics seems to generate a group of stable, mature and well integrated donors and this is a promising result for the future.

Keywords: Personality, Character, Sperm donors, non anonymous 


\section{Introduction}

The Swedish law granting a child conceived as a result of sperm donation the right to be given identification information about his or her donor has been in effect in Sweden since 1985. When oocyte donation was also allowed in 2003, oocyte-donation children became covered by this law as well.

Since Sweden was the first country to pass such a "non anonymous" law there has been substantial interest from researchers in other countries in how the law will work out in practice. Researchers have been interested in learning if the recipient couples inform their children? If they do, will the children on reaching legal maturity (18 years in Sweden) take the opportunity to access information about their genetic origins, trace the donor and even contact the donor? There are to our knowledge no individuals who have yet made use of this opportunity (personal communication with the infertility clinics)

Reasons for becoming a sperm donor have been researched extensively worldwide and from various different perspectives including religion, laws, politics, and financial incentive. One of the main reasons for donating seems to be an altruistic motive complemented by the fact that the prospective sperm donor knows about infertility problems and the impact on wellbeing and future of the involuntary childless couples (1-5).

There are, however, a number of other reasons that donors become donors, and there are strict rules guiding the clinic's selection of donors. In some countries financial reimbursement is vital in getting donors to donate. In Sweden there is no financial compensation except for the payment of travel and work expenses, a provision in effect for all organ-donation programs as well as for gamete donation. A man donating his sperm has no responsibilities or rights towards the child, either emotionally, financially or legally according to the law and has furthermore no right to know the identity of the couple or a child conceived after use of donated sperm. The child has (on becoming 18 years of age) the right to get in contact with the donor and to know all there is to be known about the donor from records and can also gain information from official papers. The parents of the child have no right to contact the donor or to get identification information about him unless the child at or after reaching age 18 chooses to inform his or her parents.

Daniels and colleagues (6) reviewed the willingness to donate under different regimes and found that an open non anonymous donor system attracts a different kind of men than does an anonymous system. The culture of secrecy regarding gamete donation and, in particular the anonymity of donors, is well established, although changes are occurring in a number of western countries (6). The internet is an important source for information and will probably 
become very important as a source of information for recipients, children, siblings and donors in the future (4).

In Sweden, a sperm donor can be accepted to donate from around 20 years of age until 45-50 years of age. The donor should be medically and psychological healthy, be aware of the laws concerning reproduction and preferably have children of his own this is about proven fertility and also for diminish the risk of identifying donors who will be having fertility problems of their own. For a man this time span in the age during which he may donate may set the stage for difficulties later in life when his situation has changed from what it was when he chose to donate. A decision made at the age of 25 might be crystal clear for the individual at that time but might take on other dimensions 20 years later for the same person because of unpredictable changes in his situation, life events experienced and even the nature of society. For most individuals the possible impact of one's decision later on in life might seem irrelevant at the time of the decision and seen by the individual as his responsibility alone. When additional and even unknown persons are involved in a process such as sperm donation there may be other factors to be taken into consideration, factors that affect all other involved individuals. Actually calculating how many children with biological roots a donor might be linked to may seem like a very hypothetical exercise for a donor to make at the time of donation. Yet according to the Swedish National Board of Health and Welfare recommendations (during this study period but changed in 2010 i.e. there is now no recommendation on number of children), each donor can be involved in the conception of 6 children (even more if treatment is offered for siblings) and a donor can of course also produce his own children before and after donation. The nature and identity of the recipient couples for the donor children might also be of concern later on in life for the donor (5).

Questions such as "did the clinics choose the right parents/couples?" and "were the parents interviewed and assessed in an acceptable way?" may arise.

Consequently knowing about the sperm donor's personality and character are of importance at the time of recruitment as one means of predicting and evaluating the donor's decision and motives as well as assessing if his personality is stable.

Thus the principal aim of this study was to investigate whether men who became donors differ in their personality from the comparison group of Swedish men in the same age group. We also wanted to study if being married and having children is of importance as concerns the issue of personality.

\section{Method}


The Swedish multicenter study on gamete donation is a prospective longitudinal study of donors. All the infertility clinics performing gamete donation in Sweden - at the University Hospitals in Stockholm, Gothenburg, Uppsala, Umea, Linkoping, Orebro, and Malmoe participate in the multicenter study.

\section{Participants and procedure}

During the period 2005 to 2008 consecutive samples of sperm donors were approached regarding participation.

All men who were accepted as donors of sperm were approached for study participation. The only exclusion criterion was that the study participants had to speak and read Swedish. Participants completed the Temperament and Character Inventory (TCI)(7), at the time of acceptance and answered questions about demographic data. Of 156 eligible donors who were approached, 119 (76\%) accepted participation and completed the first questionnaire. The reasons for refraining from participating were mainly that taking part would be too personal and it would be too time consuming to fill out the forms i.e. the TCI in the project. The TCI takes around 30-40 minutes to complete. Out of these 119 sperm donors 4 people had to be excluded due to many missing items in TCI resulting in 115 participating donors with an age range from 18 to 56 years. Donors who were not accepted due to poor sperm quality or other psychological or physiological reasons were not asked to participate in this study.

Donors were recruited for donation programs primarily through advertisements in local papers and through blood donation programs as well as from information provided on each clinic's homepage. The process in recruitment was mostly as follows: Potential donors spoke with the donor nurse coordinator on the phone who gave a general review of the principals of sperm donation including the medical procedure and the social consequences. The donor was then scheduled for a visit at the clinic and the potential donors completed a medical questionnaire to get information about surgical, medical, and social history. The coordinator then conducted the assessment of the donor's motivation and compliance for the program. The donors-to-be also received written information about the donation process. The potential donors were then invited to an interview with the responsible physician who took a medical and psychological history and gave information on legal and ethical issues. In the next step, donor candidates were assessed and evaluated by the clinic psychologists. If approved, the potential donor was registered for donation. 
The men in the study completed the questionnaire used to assess their personality and character once they had been accepted in the donation program at the appropriate clinics. This assessment usually took place after the interviews and medical examination at each clinic. Participation was rewarded with gift vouchers (worth approximately 12 Euro).

\section{Comparison group}

The comparison group consists of 115 men and matched for age from the normative study by Brändström et al. (2008) (8). The normative data for the Swedish TCI are based on a sample of 2322 individuals aged 13 to 80 years. In this study the inclusion criteria for the subjects of ages above years 20 were to be a resident of Sweden and a Swedish citizen. The group of men were randomly recruited from the county population register. 


\section{Temperament and Character Inventory (TCI)}

The Temperament and Character Inventory (TCI) based on Cloninger's personality model was used for measuring personality characteristics (8).

Cloninger started to develop the model at the beginning of 1980s. During this time the research was mainly focused on interactions between genes and environment and their impact upon personality characteristics (temperament dimensions) as key constructs of psychopathological phenomena. This research led to a development and expansion of the model during late 1980s and beginning of 1990 into a psychobiological model of personality were he also included the character dimensions. In this later model Cloninger combined knowledge from several fields including genetics, psychology and psychiatry, social and cultural theories into a testable model (9).

The model measures four dimensions of temperament and three dimensions of character. The temperament dimensions are traits that are moderately heritable and moderately stable throughout life. These dimensions refer to individual differences in conditioned emotional responses, such as anger, fear, and disgust, specifically Novelty Seeking, Harm Avoidance, Reward Dependence, and Persistence. Character dimensions represent traits that are weakly inherited and moderately influenced by social learning. Character refers to individual differences in goals, values and self-conscious emotions such as shame, guilt and empathy. The character dimensions are Self-Directedness, Cooperativeness, and Self-Transcendence. Detailed descriptions of the dimensions are available elsewhere (10). The Swedish version of the TCI has been validated and its reliability has been tested in clinical and non-clinical samples $(8,11-13)$. One of the reasons to use TCI in this study is its capacity to detect personality deviations such as extreme temperament dimensions and immature character which have been shown to indicate vulnerability to psychiatric diseases $(7,10,14)$.

\section{Demographic data}

Data on marriage status, biological children of their own, age and occupation as well as if the donor was known to the recipient couples were collected with study specific items in the questioner.

\section{Statistics}

All analyses were performed using the IBM® SPSS ${ }^{\circledR}$ Statistics for Windows, Release. 18.0.1. 2009. In order to compare mean scores of matched samples we used Paired Samples T-test. 
We also applied Chi-Square Tests, Contingency Coefficient in order to evaluate the association between two nominally scaled variables. In order to test for differences in personality between various family situations and known or unknown receivers we used Oneway Anova followed by Post Hoc Tests (Tukey because of equal variances).

Furthermore, multiple analyses of variance (MANOVA) were calculated with the TCIsubscales as dependent variables and known versus unknown receivers as fixed factor in the model.

The study was approved by The Region Ethical Review Board in Linköping

\section{Results}

Demographic characteristics are presented in Table 1. Mean age for the donors was $33.8 \pm$ 7.8 years with a range from $18-56$ years. About one third $(36.5 \%)$ of the donors had biological children of their own with a range of from one to four children with the majority having one or two (77.5\%). Twelve (10.4\%) of the donors had donated before. In this study, five $(4.3 \%)$ of the donors were so called "known donors" i.e. the recipient couples and the donors were known to each other. These "known donors" showed no significant differences in personality dimensions compared to the "unknown donors".

With regard to personality, we found significant differences on the Temperament dimension Harm Avoidance between the sperm donors and the comparison group with lower means for sperm donors $(\mathrm{p}=.002 ; 95 \% \mathrm{CI}:-3.74--0.85)$. This indicates that the sperm donors described themselves as less worried, uncertain, shy and less subject to fatigue (Table 2).

Furthermore, we also found significant differences on the Character dimensions where the sperm donors showed higher means on Self Directedness ( $p=.002$; 95\%CI: $0.97-4.19)$. This indicates that they perceived themselves as more autonomous individuals with capacity to responsibility, to behave in a more goal directed manner, to be resourceful and self-acceptant then the comparison group.

The sperm donors also showed significantly higher means on Cooperativeness $(p=.001$; 95\%CI: $0.75-2.95)$. This means that they described themselves as being more integrated with society and having a greater capacity for identification with and acceptance of other people then the comparison group.

In order to test for relationships between personality traits and family situation a One-way Anova was performed. Significant differences were found for Harm Avoidance $(F=8.33 ; p \leq$ 0.001) with significant Post Hoc Test results where the donors who were married or living 
together with someone showed significantly $(\mathrm{p} \leq 0.001)$ lower scores (mean 8.1 vs 4.0) compared to donors who were single. That means that the donors who were living single described themselves as more pessimistic, passive avoidant, fearing uncertainty, being shy, or tending to become quickly fatigued compared to those who were married or living together with someone.

Significant differences were also found for Persistence $(F=4.38 ; p=0.015)$ with significant Post Hoc Test results where the donors who were married or living together with someone showed significantly $(\mathrm{p}=0.014)$ higher scores compared to men who were single (mean 5.4 vs 4.3). This means that those who were married or living together with someone described themselves as being quite well able to resist extinction of behaviour (being more persistent). On Self Directedness significant differences $(F=7.67 ; p=0.001)$ with significant Post Hoc Test results $(\mathrm{p} \leq 0.001)$ were evident for the donors who were married or living together with someone as they showed higher scores compared to men who were single (mean $36.1 \mathrm{vs}$ 31.8). That means that those who were married or living together with someone described themselves as individuals with more capacity to take responsibility, to behave in a goal directed manner, to be resourceful and self-acceptant and to behave in a manner guided by meaningful values and goals compared to singles.

In order to compare relationships between personality for the men who donated their sperm to a known recipient with those of donors who donated to unknown recipients we applied MANOVA and found no significant main effect (Pillai's trace $=.026 ; \mathrm{F}=0.41 ; \mathrm{p}=.895 ; \eta^{2}=$ .03 ; power $=.18)$ and no significant Between-Subjects Effects.

Furthermore, we found no significant association between personality and educational levels for men who donated to a "known" or "unknown" recipient and no association between personality and family situation for "known" and "unknown" sperm donors.

Furthermore we also tested for differences on personality and age between those without and with children without significant differences accept on age where those without children were significantly younger ( $\mathrm{p} \leq 0.001$; mean age 31.3 vs 38.0$)$. 


\section{Discussion}

The results from the present study indicate that the sperm donors in this study scored lower on Harm Avoidance than the comparison group. This dimension has been found in other studies to indicate vulnerability to psychiatric change decreases $(8,12,14)$. Furthermore the sperm donors were all in the normal range of character which means that the donors perceived themselves as autonomous individuals with capacity to take responsibility, who can behave in a goal directed manner and be resourceful and self-acceptant. They also described themselves as persons well integrated in society and having a capacity for relatively high identification with and acceptance of other people. These results are promising and of significance for the individuals, the clinic and the recipient couples in the future and for maintaining the recruitment selection process. Individuals having these characteristics might be expected to be able to cope with the uncertainty about the outcome of the donation and future contacts with the children resulting from the donation.

Nearly half of the donors were in a relationship; $43 \%$ were married and $36 \%$ had children of their own that is also promising for the future since men who were in a relationship described themselves as individuals with good capacity to take responsibility, to behave in a goal directed manner, to be resourceful and self-acceptant and to behave guided by meaningful values and goals compared to the donors who were living single.

Traditionally, university students are the group most commonly targeted for semen donation especially where a financial incentive is offered. In the 1990s, Cook and Golombok showed that donors from 14 clinics were on average 24 -years old and $81 \%$ were young single students (15). In a study from the USA where donors were interviewed and psychologically tested the vast majority of the men were motivated by the financial compensation and around $29 \%$ stated that they would be willing to have their identity placed in the records for potential offspring (1). In some countries there is a change in progress towards finding more mature sperm donors. In the United Kingdom, the Human Fertilization Embryology Authority (HFEA) showed that $69 \%$ of donors between 2004 and 2005 were over 30 years of age and $45 \%$ had children of their own (16). The HFEA stated that...

“today's sperm donors are much more likely to be family men in their 30s than the old stereotype of hard-up medical students" (http://www.hfea.gov.uk/en/1109.html (21Dec 2010, date last accessed). This could be interpreted to be the positive effect of the removal of donor anonymity attracting more men who have reasons for donating other than financial motives. 
Our results together with other investigations indicate that this might be seen as a shift in the profile of men donating their sperm.to more mature individuals. All involved in the process of semen donation gain from this; the clinic in the recruitment process, the recipient couples and eventually the child if there is to be a disclosure and perhaps a contact in the future.

The literature shows that different recruitment models and legal rules for sperm donation attract different persons as potential donors. Financial compensation for sperm donation appears to attract egoistic donors who prefer to be anonymous and apparently are generally motivated by the payment (17-19).

Riggs and Russell (20) shows in their new study on 1428 sperm donors from Australia, Canada, the UK and the USA that the altruistic motivation was the primary motivation for the men but their results also indicated the men between 26-45 years of age also donated for the reasons that they had a desire to procreate. The men in this age group were also more motivated to stay anonymous towards the child to be (20).

A recent study on anonymous donors, including both sperm and oocyte donors, found that $50 \%$ of sperm donors have thought about the wellbeing of their offspring and also that $68 \%$ show a wish to know the number of their offspring. In addition, $50.8 \%$ wanted information about their offspring, $14.3 \%$ stated that they view their relationship with offspring as being a relationship with a child "like my own child" (5).

There are not to our knowledge many studies that have used and published personality inventories on sperm donors. Klock and Covington (21) have recently performed a MMPI test on potential oocyte donors in the United States and found that that one of the most important results of the MMPI-2 evaluation of oocyte donors was the need to "pay attention to the validity scale L when considering donor selection". The L Scale, also referred to as the "lie scale", was developed to identify attempts by people to present themselves in a positive light. People who score high on this scale deliberately try to present themselves in the most favourable way possible, attempting to hide shortcomings or unfavourable characteristics (21). This can be central to the donor selection process particularly if a financial incentive is the primary motivation for potential gamete donors.

In our recent study on Swedish oocyte donor's personality we found that the oocyte donors described themselves as less worried, fearful, shy and fatigued and as more persistent compared to a comparison group of women in reproductive age. This set of personality characteristics may increase the probability for success in carrying out different tasks and 
might be of significance for the individual's management of their donation both in the long term as well as in the short term (22).

Despite the careful advice of the most experienced team, no one can fully predict how someone will feel about their decisions tomorrow, let alone twenty years in the future. The Swedish law on gamete donation is intended to take the offspring's needs into consideration but not the donors' needs. Therefore the clinics must take substantial responsibility for assessing, discussing and reflecting on the donor's motives and knowledge about the procedures and the future.

For some individuals, meeting with and informing a child about oneself and the motivation for a donation made 20 years earlier may be an overwhelming experience to. In addition, since the child has the right to learn the identity of the donor, the child might choose to observe his or her donor without the donor knowing that the now grown child is doing this.

A limitation in this study could be that the men in our sample have not answered any questions about country of origin or ethnicity nor have they answered questions asking if they were hetero or homosexual - questions about race and sexuality are by tradition mostly ignored in research of this kind in Sweden. In the clinical setting we know that most applications come from men whom we can assume are of Nordic background and ethnicity and sexuality should not be an issue when donors are to be selected. Our donors will not be anonymous to the child in the future (if told by the parents) but are not chosen by the recipient couples since the selection process is by law done by the physician at the clinic. There is not, to our knowledge, any study that has reported any data concerning country of origin and ethnicity of donors and infertility patients in Sweden, but we know from other surveys that there are very few non Caucasian donors and that the demand for donors with other than Caucasian background is widespread in settings where the problem of infertility is being addressed.

A strength in this study is that we have asked all sperm donors that have been accepted for donation in Sweden and $75 \%$ agreed to participate. One limitation is that we do not have any information about the men who declined study participation. Due to ethical considerations, we were unable to ask those men for information related to their personality or other demographics. We believe that the reasons stated for lack of participation (questionnaire was 
considered time consuming or unwillingness to provide information about their personality) were an honest reply form the men who choose not to participate.

One other limitation is that we do not have any information about the men who were not accepted for the program and the explanations for this. Reasons for not being accepted are of interest for the screening procedures as is the rationale for those men who dropout without having donated. It is essential that we learn more about what information is needed and the potential donor's experience of the screening process.

The recruitment process and the information given to potential donors may vary between clinics but we have in this study shown that the men who are accepted for the program were all in the normal range of character and also demonstrated a mature personality and a stable character.

Since a sperm donation might be seen as a life long commitment and not merely as a donation of a cell to a couple who is not known at the time of recruitment, there is great responsibility of the clinics to choose a suitable donor and to handle the donor respectfully in the future. Out of consideration for the donor who have contributed to both society and to individuals the clinics should inform the donor when an individual has sought out information about his or her donor this would help us to get a better picture of reactions and needs for the donor in long perspective.

\section{ACKNOWLEDGEMENTS}

This study was supported by grants from the Medical Research Council of Southeast Sweden (FORSS). We thank all the personal at the 7 IVF-Clinics that have been involved in this study. We also thank Merck Serono for valuable support during the implementation of the study.

\section{Conflicts of interest: None}

Financial disclosure: None.

\section{Contribution to Authorship}

Gunilla Sydsjö Research idea, design, preparation of the manuscript, responsible for the final preparation of the manuscript

Claudia Lampic Research idea, design, preparation of the manuscript, 
Sven Brändström

Johannes Gudmundsson

Per-Olof Karlström

Ann Kjellberg-Thurin

Nils Gunnar Solensten

Agenta Skoog Svanberg
Analysis of data, preparation of the manuscript

Data collection, preparation of the manuscript

Data collection, preparation of the manuscript

Data collection, preparation of the manuscript

Data collection, preparation of the manuscript

Data collection, design, preparation of the manuscript, analysis of data

\section{Ethics}

Human Research Ethics Committee; Faculty of Health Sciences, Linköping University nr Dnr: M129-05-050223, T113-07 080122 approved the study.

\section{Word Count}

\section{5}

\section{References}

1. Shover LR, Rothman SA, Collins RL. The personality and motivation of semen donors a comparison with oocyte donors. Hum Reprod. 1992;7:575-579.

2. Pedersen B, Nielsen AF, Lauritsen JG. Psychosocial aspects of donor insemination. Sperm donors-their motivations and attitudes to artificial insemination. Acta Obstet Gynecol Scand. 1994;73:701-5.

3. Ekerhovd E, Faurskov A, Werner C. Swedish sperm donors are driven by altruism, but shortage of sperm donors leads to reproductive travelling. Ups J Med Sci. 2008;113:305-13.4.

4. Thorn P, Katzorke T, Daniels K. Semen donors in Germany: a study exploring motivations and attitudes. Hum Reprod. 2008;23:2415-20. 
5. Jadva V, Freeman T, Kramer W, Golombok S. Sperm and oocyte donors' experiences of anonymous donation and subsequent contact with their donor offspring.Hum Reprod. 2010; 26:638-45

6. Daniels K. Anonymity and openness and the recruitment of gamete donors. Part I: semen donors. Hum Fertil. 2007;10(3):151-8. Review.

7. Cloninger, C. R., Przybeck, T. R., Svrakic, D. M., \& Wetzel, R. D. (1994). The Temperament and Character Inventory (TCI). A guide to its development and use. St. Louis, Missouri: Center for Psychobiology of Personality, Washington University.

8. Brändström S, Sigvardsson S, Nylander PO, Richter J. The Swedish Version of the Temperament and Character Inventory (TCI). A cross-validation of age and gender influences. European Journal of Psychological Assessment 2008; 24: 14-21.

9. Brändström, S. (2009). Personality and its complexity: An investigation of the Swedish version of the Temperament and Character Inventory (Doctoral dissertation). Available from Linköping University . http://urn.kb.se/resolve?urn=urn:nbn:se:liu:diva-17839

10. Cloninger C.R. (2004), Feeling Good: The Science of Well Being. New York: Oxford University Press

11. Brändstrom S, Schlette P, Przybeck T R, Lundberg M, Forsgren T, Sigvardsson S, Nylander P O, Nilsson L G, Cloninger R C, \& Adolfsson R. (1998) Swedish normative data on personality using the Temperament and Character Inventory. Compr Psychiatry; 1998; $39 ; 122-128$.

12. Engström, C., Brändström, S., Sigvardsson, S., Cloninger, C. R., \& Nylander, P.O. Bipolar disorder III. Harm avoidance a risk factor for suicide attempts. Bipolar Disorder2004; 6, 130-138.

13. Pettersson K, Brändström S, Toolanen G, Hildingsson C, \& Nylander P. O. Temperament and character: prognostic factors in whiplash patients? European Spine Journal, 2004;6:130138.

14. Richter J, Brändström S. Personality Disorder Diagnosis by Means of the Temperament and Character Inventory (TCI). Compr Psychiatry 2009;50:347-52.

15. Cook R, Golombok S. A survey of semen donation: Phase II-the view of the donor. Hum Reprod. 1995;10:951-9. 
16. Human Fertilisation and Embryology Authority. Who are the UK's sperm donors? Fertility regulator presents national picture of the people who donate. Stereotype of hard-up medical students a thing of the past. London, UK HFEA, October 2005. http://www.hfea.gov.uk/en/1109.html (21Dec. 2010, date last accessed)

17. Ernst E, Ingerslev H J Schou O Stoltenberg M Attitudes among sperm donors in 1992 and 2002: a Danish questionnaire survey. Acta Obstet Gynecol Scand. 2007; 86(3):327-33.

18. Godman KM, Sanders K, Rosenberg M, Burton P. Potential sperm donors', recipients' and their partners' opinions towards the release of identifying information in Western Australia. Hum Reprod. 2006; 21:3022-6.

19. Yee S. Review 'Gift without a price tag': altruism in anonymous semen donation. Hum Reprod. $200 ; 24(1): 3-13$.

20. Riggs DW and Russell. Characteristics of men willing to act as sperm donors in the context of identity-release legislation. Hum Reprod. 2011;26:266-272.

21. Klock SC, and Covington SN. Minnesota Multiphasic Personality Inventory (MMPI-2) profiles in the assessment of ovum donors. Fertil Steril. 2009;94(5):1684-8.

22. Sydsjö G, Lampic C, Brändström S, Gudmundsson J, Karlström P, Solensten N, ThurinKjellberg A, Svanberg A. . Personality characteristics in a Swedish national sample of identifiable oocyte donors.BJOG. 2011 Apr 11. [Epub ahead of print] 
Table 1. Socio demographics of the 115 sperm donors.

Donors

$\mathrm{n}=115$

\section{Education:}

1 Comprehensive school

2 Senior High school

3 Senior High school + some college

4 University

Family situation:

1 Single

2 Have a partner

22

19

3 Married/cohabiting

50

43

Missing information

1

1

Biological children of their own 
2 Table 2. Temperament and Character dimensions and age for sperm donors and comparison group.

\begin{tabular}{|c|c|c|c|c|c|}
\hline & Donors & Comparison group & $\begin{array}{c}\text { Donors living as } \\
\text { single }\end{array}$ & $\begin{array}{l}\text { Donors in a steady } \\
\text { relationship }\end{array}$ & $\begin{array}{l}\text { Donors married or } \\
\text { livino tooether }\end{array}$ \\
\hline & $\mathrm{n}=115$ & $\mathrm{n}=115$ & $\mathrm{n}=42$ & $\mathrm{n}=22$ & $\mathrm{n}=50$ \\
\hline Novelty Seeking & $20.7 \pm 4.7$ & $21.1 \pm 5.3$ & $20.4 \pm 5.6$ & $20.7 \pm 4.5$ & $20.7 \pm 3.4$ \\
\hline Harm Avoidance & $9.6 \pm 5.1$ & $11.9 \pm 5.4^{* *}$ & $12.0 \pm 5.8$ & $8.6 \pm 4.1$ & $8.1 \pm 4.0 * * * \dagger$ \\
\hline Persistence & $4.8 \pm 1.9$ & $4.5 \pm 1.8$ & $4.3 \pm 2.1$ & $4.6 \pm 1.8$ & $5.4 \pm 1.7^{* \dagger}$ \\
\hline \multicolumn{6}{|l|}{ Character } \\
\hline Self-Directedness & $34.2 \pm 5.5$ & $31.7 \pm 6.5^{* *}$ & $31.8 \pm 5.5$ & $34.5 \pm 6.5$ & $36.1 \pm 4.3$ \\
\hline Cooperativeness & $34.6 \pm 4.4$ & $32.7 \pm 4.4 * * *$ & $33.8 \pm 4.6$ & $33.7 \pm 5.3$ & $35.5 \pm 3.6^{* * * \dagger}$ \\
\hline
\end{tabular}

$* \mathrm{p}<.05 ; * * \mathrm{p}<.01 ; * * * \mathrm{p}<.001$. 
